CLINICAL STUDY

\title{
Partial restoration of GH responsiveness to ghrelin in Cushing's disease after 6 months of ketoconazole treatment: comparison with GHRP-6 and GHRH
}

\author{
Silvia R Correa-Silva ${ }^{1}$, Sérgio O Nascif ${ }^{1}$, Patrícia Molica ${ }^{1}$, Larissa B P C Sá ${ }^{1}$, José G Vieira ${ }^{1,2}$ \\ and Ana-Maria J Lengyel ${ }^{1}$ \\ ${ }^{1}$ Division of Endocrinology, Universidade Federal de São Paulo, Rua Pedro de Toledo, 910, CEP 04039-002 São Paulo, SP, Brazil and ${ }^{2}$ Instituto Fleury, \\ Avenida General Valdomiro de Lima, 508, CEP 04344-903 São Paulo, Brazil
}

(Correspondence should be addressed to S R Correa-Silva; Email: dra.silviaregina@terra.com.br)

\begin{abstract}
Objective: In Cushing's disease (CD), GH responsiveness to several stimuli, including ghrelin, GHRP-6, and GHRH, is blunted. Recovery of GH secretion after remission of hypercortisolism after transsphenoidal surgery, radiotherapy, or adrenalectomy is controversial. There are no studies evaluating the effect of primary clinical treatment with ketoconazole on GH secretion in CD. The aim of this study is to compare ghrelin-, GHRP-6-, and GHRH-induced GH release before and after ketoconazole in CD.

Design: GH responses to ghrelin, GHRP-6, and GHRH of eight untreated patients with CD (mean age: $33.8 \pm 3.1$ years; body mass index: $28.5 \pm 0.8 \mathrm{~kg} / \mathrm{m}^{2}$ ) were evaluated before and after 3 and 6 months of ketoconazole treatment, and compared with 11 controls $(32.1 \pm 2.5 ; 25.0 \pm 0.8)$.

Methods: Serum GH was measured by an immunofluorometric assay and urinary free cortisol (UFC) by liquid chromatography and tandem mass spectrometry.

Results: After ketoconazole use, mean UFC decreased significantly (before: $222.4 \pm 35.0 \mu \mathrm{g} / 24 \mathrm{~h}$; third month: $61.6 \pm 10.1$; sixth month: $39.1 \pm 10.9$ ). Ghrelin-induced GH secretion increased significantly after 6 months (peak before: $6.8 \pm 2.3 \mu \mathrm{g} / \mathrm{l}$; sixth month: $16.0 \pm 3.6$ ), but remained lower than that of controls (54.1 \pm 11.2$)$. GH release after GHRP-6 increased, although not significantly, while GH responsiveness to GHRH was unchanged.

Conclusions: Ghrelin-induced GH release increases significantly after 6 months of ketoconazole treatment in CD. This could suggest that a decrease in cortisol levels during this time period can partially restore glucocorticoid-induced GH suppression in CD. GH-releasing mechanisms stimulated by ghrelin/GHS could be more sensitive, as no changes in GHRH-induced GH release were observed.
\end{abstract}

European Journal of Endocrinology 161 681-686

\section{Introduction}

GH secretion is modulated by GHRH and somatostatin (SRIF), but GH secretagogues (GHS) might also have a role, acting at both hypothalamic and pituitary receptors $(1,2)$. Ghrelin, the endogenous ligand of GHS receptors (GHS-R), is present in the stomach and in the hypothalamus (3). The active acylated peptide has a different chemical structure than GHS (4). Ghrelin and GHRP-6, a GHS, are able to induce GH, ACTH, and cortisol release (5). Their main site of action is the hypothalamus, as these effects are reduced/abolished in hypothalamic-pituitary disconnection (6, 7). Ghrelin/GHS action on GH secretion probably involves activation of GHRH neurons, with increased GHRH release, amplification of GHRH effects at the somatotroph and functional antagonism of $\operatorname{SRIF}(8,9)$. GHS/ghrelin and GHRH bind to separate receptors and activate different intracellular mechanisms at the somatotroph. GHRH stimulates cyclic AMP and protein kinase A pathways (3), while ghrelin and GHRP-6 activate protein kinase $\mathrm{C}$ signal transduction $(2,3)$. Moreover, there is a synergistic effect of ghrelin/GHS and GHRH on GH release (4).

In patients with Cushing's disease (CD), GH responsiveness to several stimuli, including ghrelin, GHRP-6, and GHRH, is blunted (10-12). The mechanisms involved in the inhibitory effect of chronic hypercortisolism on GH secretion are not clear. An increase in hypothalamic SRIF release is unlikely to have a major role (11). A decrease in GHRH secretion (13) and a direct effect of glucocorticoids at the somatotroph (14) might be involved.

It has been shown that GH secretion ability can be acutely enhanced in $\operatorname{CD}(14,15)$. However, there are several reports of lack of recovery of GH secretion after 
remission of hypercortisolism with transsphenoidal surgery (TS) or radiotherapy (RT) (16-22), which could be due, at least in part, to treatment-induced somatotroph damage. In contrast, early normalization of GH secretion has been observed when adrenalectomy is performed, and the pituitary is intact (16).

Ketoconazole is a steroidogenesis inhibitor that has been largely used for the treatment of Cushing's syndrome, as it is able to normalize cortisol levels in $70 \%$ of these patients (23) and rarely causes hepatic damage (24).

There are no data in the literature about the effect of clinical treatment with ketoconazole on GH secretion in patients with $\mathrm{CD}$.

Therefore, the aim of this study was to evaluate $\mathrm{GH}$ responses to ghrelin and GHRP- 6 before and after 3 and 6 months of ketoconazole use in untreated patients with CD. GHRH-induced GH release was additionally studied, as it stimulates GH secretion via different mechanisms than those of ghrelin/GHRP-6.

\section{Material and methods}

\section{Subjects}

Eight female patients with CD were studied before any treatment. Six had microadenomas and two had small macroadenomas (maximal tumor diameters of 11 and $13 \mathrm{~mm})$. Their mean age ( \pm s.e.M.) was $33.8 \pm 3.1$ years (range: 19-41) and their body mass index (BMI) was $28.5 \pm 0.8 \mathrm{~kg} / \mathrm{m}^{2}$ (range: $26.2-32.1$ ). Diagnosis of $\mathrm{CD}$ was established by clinical features and standard hormonal criteria, including increased free urinary cortisol excretion, lack of suppression of serum cortisol after dexamethasone (1 mg orally overnight), normal or high basal plasma ACTH and serum cortisol levels at $0800 \mathrm{~h}$, and positive desmopressin (DDAVP) test. Magnetic resonance imaging showed a pituitary adenoma in all patients. None of the patients was on replacement therapy for hypopituitarism before surgery. At diagnosis, all patients had normal renal function and four had secondary diabetes mellitus. One patient was treated with diet, two with metformin, and one with metformin and insulin.

After the end of the experimental protocol, all patients were submitted to TS and the diagnosis of ACTH-secreting tumor was confirmed by positive ACTH immunostaining of the excised pituitary adenoma.

Eleven normal subjects (four women and seven men) with a mean age of $32.1 \pm 2.5$ years (range: $20-47$ ) and BMI of $25.0 \pm 0.8 \mathrm{~kg} / \mathrm{m}^{2}$ (range: $20.9-30.8$ ) were also studied. They were free of any medication during the study protocol. The women were tested in the early follicular phase of their menstrual cycle.

\section{Study protocol}

The experimental protocol was approved by the Ethics Committee of UNIFESP, and all subjects gave prior informed consent.

Each subject was submitted to three tests, in random order, with a minimum interval of $48 \mathrm{~h}$, with acylated ghrelin (Neosystem, Strasbourg, France), GHRP-6 (Bachem, San Carlos, CA, USA), or GHRH (1-29) NH2 (Clinalfa, Läufelfingen, Switzerland). Patients with CD were studied before and after 3 and 6 months of ketoconazole use, which was given at a dose of $400 \mathrm{mg} /$ day initially, administered two or three times a day. Urinary free cortisol (UFC) was measured every month, and the dose of ketoconazole was titrated accordingly (400-1200 mg/day).

All tests were performed after an overnight fast, and the subjects remained recumbent throughout. Patients were advised to take ketoconazole before the tests at the same time as usual $(0600 \mathrm{~h})$. At $0800 \mathrm{~h}$, an indwelling catheter was inserted into an antecubital vein and was kept patent by a saline infusion. The tests started 45 min later. After the first blood sample, each subject received ghrelin or GHRP-6 at a dose of $1 \mu \mathrm{g} / \mathrm{kg}$ i.v. or GHRH at a dose of $100 \mu \mathrm{g}$ i.v. Blood samples were obtained every 15 min until $120 \mathrm{~min}$ for hormonal and biochemical determinations.

\section{Assays}

Serum GH was measured in duplicate by an immunofluorometric assay (Wallac, Turku, Finland). The sensitivity of the method is $0.01 \mu \mathrm{g} / \mathrm{l}$, with mean inter- and intraassay coefficients of variation (CV) of 7 and $6.7 \%$ respectively. Serum cortisol levels were measured in duplicate by a fluoroimmunoassay (Wallac), with sensitivity of $0.2 \mu \mathrm{g} / \mathrm{dl}$, and mean inter- and intraassay CV of 8.2 and $6.2 \%$ respectively. Insulin-like growth factor-1 (IGF1) levels were determined by an immunochemiluminometric assay (DPC, Los Angeles, CA, USA), with sensivity of $20 \mathrm{ng} / \mathrm{ml}$, and mean inter- and intraassay CV of 6.5 and $3.8 \%$ respectively. UFC was measured by liquid chromatography and tandem mass spectrometry (Fleury Laboratory, São Paulo, Brazil) (25), with sensitivity of $<1 \mu \mathrm{g} / \mathrm{l}$, and mean inter- and intraassay CV of 7.7 and $4.4 \%$ respectively.

\section{Statistical analysis}

Repeated-measures ANOVA or Friedman's ANOVA was used to compare data within the same group when appropriate. Unpaired $t$-test or Mann-Whitney rank sum test was performed to compare data between patients and controls. The area under the curve (AUC) was calculated by trapezoidal integration. Delta $(\Delta)$ values subtracting baseline or during treatment were also calculated. Spearman's correlation coefficient was 
calculated when appropriate. Undetectable GH $(\mu \mathrm{g} / \mathrm{l})$ values were considered to be equal to 0.01 for statistical purposes. $P<0.05$ was considered statistically significant. Results are reported as mean \pm s.E.M.

\section{Results}

\section{Basal values and clinical data}

There was no difference in age between patients and controls. Before treatment, patients with $\mathrm{CD}$ had significantly higher BMI values compared with the control group. There was a trend to a decrease in mean BMI during treatment $(P=0.08)$, and after 6 months, BMI values were similar to those of controls. Basal GH and IGF1 levels in CD were not different than those of controls initially and did not change significantly during treatment. At diagnosis, patients with $\mathrm{CD}$ had higher basal serum cortisol levels compared with controls. These values decreased significantly during ketoconazole use, but were still higher than those of controls at the third and sixth month. In CD, mean fasting glucose levels were higher than those of controls and decreased significantly during treatment, becoming similar to the control group at the sixth month (Table 1). All diabetic patients improved their glycemic control with ketoconazole treatment, with normalization of glucose levels in one patient and insulin withdrawal in another.

\section{UFC values}

Patients with CD had mean UFC $(\mu \mathrm{g} / 24 \mathrm{~h})$ of 222.4 \pm 34.5 at the time of the diagnosis. After 3 and 6 months of ketoconazole treatment, mean UFC decreased significantly to $61.6 \pm 10.1$ (mean reduction: $70 \%$ ) and $39.1 \pm 10.9$ (mean reduction: 80\%) respectively (Table 1). All patients showed a decrease in UFC values after 3 months of treatment, and after 6 months four patients had their values within the normal range, while two had UFC levels near the upper limit of normality. Only one patient did not show normalization of UFC values throughout the whole period, despite a major decrease both at the third $(74 \%)$ and sixth $(76 \%)$ month. Another patient had an 'escape' at the sixth month, after normalization in the third month. None of the patients had UFC values below the normal range throughout the treatment (Table 1).

\section{GH responses}

Patients with $\mathrm{CD}$ had significantly lower peak GH $(\mu \mathrm{g} / \mathrm{l})$ and AUC ( $\mu \mathrm{g} / \mathrm{l} 120 \mathrm{~min})$ values after ghrelin $(6.8 \pm 2.3 ; 238 \pm 88)$, GHRP-6 (2.8 $\pm 0.8 ; 107 \pm 37)$, and GHRH $(1.1 \pm 0.2 ; 64 \pm 14)$ compared with the control group (ghrelin: 54.1 $\pm 11.2 ; 3123 \pm 707$; GHRP-6: $25.7 \pm 4.5$; $1396 \pm 284$; GHRH: $11.7 \pm 3.3$; $857 \pm 267$ ). After 3 months of ketoconazole use, GH responses to ghrelin (peak: $7.9 \pm 2.2$; AUC: $273 \pm 83$ ), GHRP-6 (peak: 4.1 \pm 1.0 ; AUC: $149 \pm 30$ ), and GHRH (peak: $1.2 \pm 0.3$; AUC: $73 \pm 18$ ) did not change significantly (Figs 1 and 2). After 6 months, there was a significant increase in $\mathrm{GH}$ response to ghrelin in CD (peak: 16.0 \pm 3.6 ; AUC: $602 \pm 175$ ) compared with before treatment and also with the third month of ketoconazole use. However, GH responsiveness to ghrelin in CD remained lower than in controls. GH response to GHRP-6 (peak: $5.1 \pm 1.5$; AUC: $194 \pm 71$ ) also increased, but did not reach statistical significance (Fig. 1). Individual analysis showed that all patients, except one, had an increase in GH responsiveness to ghrelin, and this was also seen in the majority after GHRP-6 stimulation. In three patients, peak $\mathrm{GH}$ values were within the range observed in the control group, while in one patient GH levels were just below the lower limit of controls for both ghrelin and GHRP-6. The only patient who failed to increase GH values after ghrelin had lack of normalization of UFC levels during the whole study period. When this patient was excluded from the statistical analysis, no significant differences were observed. GHRH-induced GH release $(1.2 \pm 0.4 ; 69 \pm 21)$ did not change after 6 months of treatment, and only two patients reached values just above the lower limit of controls.

No correlations were found between $\Delta$ BMI, $\Delta$ UFC, $\Delta$ basal cortisol or $\Delta$ fasting glucose, and $\Delta \mathrm{GH}$ peak and AUC after 6 months of treatment. Negative correlations

Table 1 Basal values and clinical data of patients with Cushing's disease (CD; $n=8)$ before and after 3 and 6 months of ketoconazole treatment and of controls $(n=11)$.

\begin{tabular}{lcrrr}
\hline & & & \multicolumn{2}{c}{ CD } \\
\cline { 3 - 5 } & Controls & Before & Third month & Sixth month \\
\hline Age $($ years $)$ & $32.1 \pm 2.5$ & $33.8 \pm 3.1$ & & \\
BMl $\left(\mathrm{kg} / \mathrm{m}^{2}\right)$ & $25.0 \pm 0.8$ & $28.5 \pm 0.8^{*}$ & $27.6 \pm 0.7^{*}$ & $27.2 \pm 0.8$ \\
GH $(\mu \mathrm{g} / \mathrm{l})$ & $0.1 \pm 0.07$ & $0.3 \pm 0.1$ & $0.2 \pm 0.03$ & $0.3 \pm 0.05$ \\
IGF1 $(\mathrm{ng} / \mathrm{ml})$ & $177.2 \pm 12.6$ & $232.4 \pm 41.6$ & $225.5 \pm 23.1$ & $220.5 \pm 30.4$ \\
UFC $(\mu \mathrm{g} / 24 \mathrm{~h})$ & & $222.4 \pm 34.5$ & $61.6 \pm 10.1^{\dagger}$ & $39.1 \pm 10.9^{\dagger}$ \\
Cortisol $(\mu \mathrm{g} / \mathrm{dl})$ & $7.9 \pm 0.7$ & $22.2 \pm 2.5^{*}$ & $16.8 \pm 1.6^{*, \dagger}$ & $14.6 \pm 1.6^{*, \dagger}$ \\
Glucose $(\mathrm{mg} / \mathrm{dl})$ & $84.6 \pm 2.2$ & $113.1 \pm 10.4^{*}$ & $101.0 \pm 6.1^{*, \dagger}$ & $92.8 \pm 5.8^{\dagger}$ \\
\hline
\end{tabular}

${ }^{\star} P<0.05$ versus controls; ${ }^{\dagger} P<0.05$ versus before treatment. 

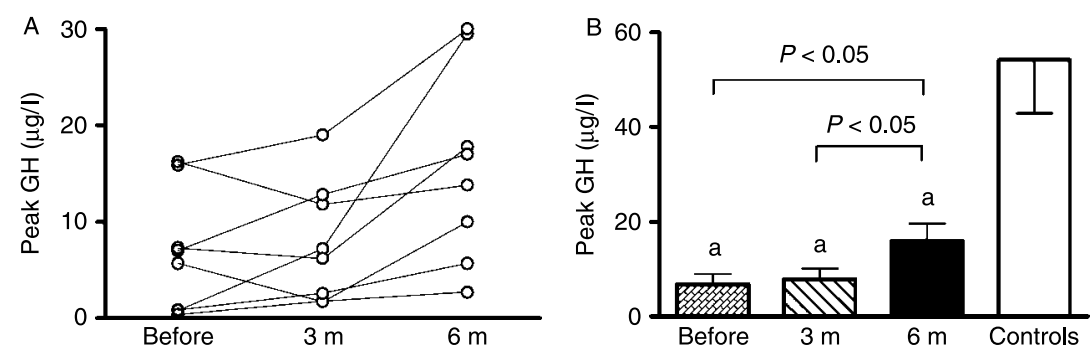

Figure 1 Individual (A) and mean GH values (B) after ghrelin administration in $\mathrm{CD}(n=8)$ before and after 3 and 6 months of ketoconazole treatment and in controls ( $n=11$; mean \pm s.E.M.; a, $P<0.05$ versus controls). between basal serum cortisol levels and GH AUC values after all peptides (ghrelin: $r=-0.762, P=0.02$; GHRP-6: $r=-0.762, P=0.02$; GHRH: $r=-0.755$, $P=0.02$ ) were observed after 6 months of treatment.

\section{Side effects}

Hunger sensation, nausea, and sleepiness were reported occasionally after ghrelin administration. Three patients had a transient and mild increase in alanine transaminase after the first month of ketoconazole administration.

\section{Discussion}

In our present study, patients with $\mathrm{CD}$ had blunted GH responses to ghrelin, GHRP-6, and GHRH before ketoconazole treatment, as previously reported by us and others (10-12). GH responsiveness to ghrelin was higher both in $\mathrm{CD}$ and controls, which could be due to the greater potency of this peptide (5).

It has been shown that adult patients with $\mathrm{CD}$ previously submitted to surgery and/or RT (16-22) have lack of recovery of GH secretion, which could be due, at least in part, to GH deficiency caused by pituitary damage. We, therefore, evaluated $\mathrm{GH}$ secretion in $\mathrm{CD}$ after pharmacological reduction or correction of hypercortisolism in patients who are not submitted to any pituitary intervention. Moreover, as most of our patients had microadenomas, with only two harboring small macroadenomas, they were likely to have an intact GH axis. It has been previously shown that acute clinical interventions such as inhibition of free fatty acids and short-term dietary restriction $(14,15)$ were able to increase GH secretion in CD. However, we did not observe significant changes in GH responses to ghrelin, GHRP-6, and GHRH after a short period (1 month) of ketoconazole use in patients with $\mathrm{CD}$, although UFC values had a considerable fall (26).

Despite major decreases in UFC levels since the third month, GH responsiveness to ghrelin only increased significantly after 6 months of ketoconazole treatment. However, it remained lower than that seen in the control group. GHRP-6-induced GH release also increased, but not significantly, while no changes in
$\mathrm{GH}$ responses to GHRH were observed. Individual analysis showed that $50 \%$ of our patients had peak GH values after ghrelin/GHRP-6 within or near the range of controls after 6 months of treatment, while only two reached this range after GHRH stimulation. At this time point, six patients had normal or near normal UFC values. The only patient who did not increase $\mathrm{GH}$ values after ghrelin had UFC values above the upper limit of normality during the entire study period. No correlation was observed between UFC or serum cortisol levels and $\mathrm{GH}$ responsiveness to ghrelin, which has already been shown with other stimuli $(21,22)$. Periods of subtle hypo- or hypercortisolism, due to the pharmacological profile of ketoconazole, cannot be totally excluded and could have contributed to the partial improvement of the somatotrophic axis in some of our patients. However, our results are similar to those obtained by Tzanela et al. who showed recovery of GH secretion after
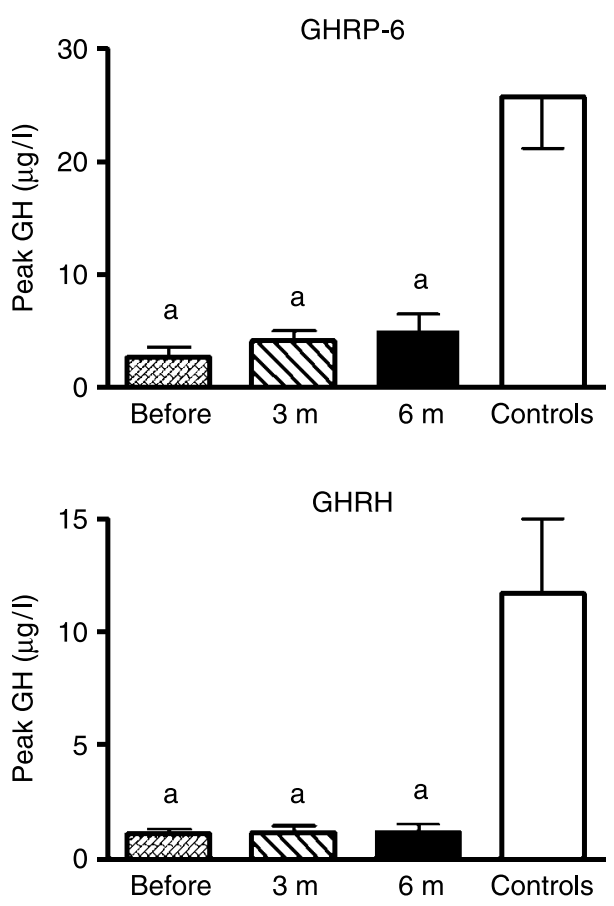

Figure 2 Mean GH values after GHRP- 6 and GHRH administration in CD $(n=8)$ before and after 3 and 6 months of treatment and in controls ( $n=11$; mean \pm s.E.M.; a, $P<0.05$ versus controls). 
pyridostigmine $+\mathrm{GHRH}$ and/or insulin tolerance test (ITT) in 50\% (two out of four) of patients with CD, who had intact pituitary function, and who were in remission 6 months after TS (21). In contrast, lower GH recovery rates have been described in the first 6 months after TS in most studies (17-19). Our results suggest that, if there is no pituitary damage, even relatively short-term periods of normal or near normal cortisol values are able to partially restore GH secretion in CD. Moreover, this is apparently unrelated to a decrease in circulating IGF1, as no significant changes in IGF1 levels were observed in our study period, confirming previous data in patients with CD after TS $(19,21)$.

Obesity and hyperglycemia, two features of hypercortisolism, are associated with blunted $\mathrm{GH}$ responses to ghrelin, GHRP-6, and GHRH $(27,28)$ and could be contributing factors to the partial recovery of $\mathrm{GH}$ axis in some cases. However, we have previously shown that blunted GH responses also occur in overweight patients with CD compared with BMI-matched controls (12). Moreover, although our patients had slightly higher BMI values initially, these values became similar to controls after 6 months of ketoconazole use, and no correlation was found between $\mathrm{GH}$ responses to ghrelin and BMI in CD, as previously reported $(12,21,22)$. Despite a significant decrease in fasting glucose levels during treatment, no correlation was found between glucose values and $\mathrm{GH}$ responsiveness to ghrelin. Therefore, the partial recovery of GH axis in some of our patients is unlikely to be due to these factors.

The possible mechanisms of decreased GH secretion and also of recovery of somatotroph responsiveness in CD remain unknown.

It has been previously suggested that glucocorticoid excess inhibits hypothalamic GHRH release (13), which could lead to chronic GHRH deficiency. In this situation, there is a lack of $\mathrm{GH}$ responsiveness to exogenous GHRH (29). Moreover, GHRH-mediated pathways at the somatotroph could also be impaired by hypercortisolism (14). Although controversial in animals (30, 31), this steroid also downregulates human GHS-R (32). Therefore, glucocorticoids could eventually interfere with ghrelin/GHS-stimulated transduction mechanisms at the somatotroph, with a possible additional effect on GHS-R located in GHRH-releasing neurons at the hypothalamus (9). As GHS/ghrelin and GHRH activate different pathways of $\mathrm{GH}$ release, the enhancement of ghrelin/GHRP-6-induced GH release after treatment together with lack of changes in $\mathrm{GH}$ responsiveness to GHRH could eventually suggest that ghrelin/GHSmodulated mechanisms are more sensitive to the decrease in circulating glucocorticoid levels than those of GHRH. Moreover, this is more pronounced for ghrelin than for GHRP-6, which could be due to the activation of multiple intracellular mechanisms in the somatotroph by ghrelin (33).

It is well established that there is a synergistic effect of ghrelin/GHS and GHRH on GH release (4). It has been recently shown that GHRH acts as a coagonist of GHS-R and increases the affinity of ghrelin by its receptor (34). Our data suggest that chronic GHRH deficiency may persist after 6 months of ketoconazole treatment, as no changes in GHRH-induced GH release were observed. This could interfere with the synergistic effect between ghrelin/GHS and GHRH, and eventually explain why $\mathrm{GH}$ responsiveness to ghrelin is not fully restored.

However, additional studies are necessary to confirm these hypotheses.

In summary, our results show that mean $\mathrm{GH}$ responsiveness to ghrelin increases, although does not normalize, after 6 months of ketoconazole treatment in CD. In $50 \%$ of the patients, GH values reach the range of controls. This could suggest that a relatively short-term decrease in circulating cortisol levels can partially restore glucocorticoid-induced $\mathrm{GH}$ suppression in CD. GH-releasing mechanisms stimulated by ghrelin/GHS could be more sensitive to the reduction in cortisol levels, as no changes in GHRH-induced GH release were observed. Further studies are necessary to clarify these hypotheses.

\section{Declaration of interest}

The authors declare that there is no conflict of interest that could be perceived as prejudicing the impartiality of the research reported.

\section{Funding}

This work was supported by FAPESP (Fundação de Amparo à Pesquisa do Estado de São Paulo; 02/14118-9).

\section{Acknowledgements}

We thank Dr Carlos Dieguez for the initial encouragement, Filomena Machado and Walkiria Miranda for technical help, and Prof. Clovis Peres and Prof. Gianni Santos for statistical assistance.

\section{References}

1 Bowers CY, Momany FA, Reynolds GA \& Hong A. On the in vitro and in vivo activity of a new synthetic hexapeptide that acts on the pituitary to specifically release growth hormone. Endocrinology $19841141537-1545$.

2 Howard AD, Feighner SD, Cully DF, Arena JP, Liberator PA, Rosenblum CI, Hamelin M, Hreniuk DL, Palyha OC, Anderson J, Paress PS, Diaz C, Chou M, Liu KK, McKee KK, Pong SS, Chaung LY, Elbrecht A, Dashkevicz M, Heavens R, Rigby M, Sirinathsinghji DJ, Dean DC, Melillo DG, Patchett AA, Nargund R, Griffin PR, DeMartino JA, Gupta SK, Schaeffer JM, Smith RG \& Van der Ploeg LH. A receptor in pituitary and hypothalamus that functions in growth hormone release. Science $1996273974-977$.

3 Korbonits M, Goldstone AP, Gueorguiev M \& Grossman AB. Ghrelin - a hormone with multiple functions. Frontiers in Neuroendocrinology 200425 27-68.

4 Kojima M, Hosoda H, Date Y, Nakazato M, Matsuo H \& Kangawa K. Ghrelin is a growth hormone-releasing hormone acylated peptide from stomach. Nature $1999 \mathbf{4 0 2} 656-660$.

5 Arvat E, Maccario M, Di Vito L, Broglio F, Benso A, Gottero C, Papotti M, Muccioli G, Dieguez C, Casanueva FF, Deghenghi R, Camanni F \& Ghigo E. Endocrine activities of ghrelin, a natural 
growth hormone secretagogue (GHS), in humans: comparison and interactions with hexarelin, a nonnatural peptidyl GHS, and GH-releasing hormone. Journal of Clinical Endocrinology and Metabolism 200186 1169-1174.

6 Popovic V, Damjanovic S, Micic D, Djurovic M, Dieguez C \& Casanueva FF. Blocked growth hormone-releasing peptide (GHRP6)-induced GH secretion and absence of the synergic action of GHRP-6 plus GH-releasing hormone in patients with hypothalamopituitary disconnection: evidence that GHRP-6 main action is exerted at the hypothalamic level. Journal of Clinical Endocrinology and Metabolism $199580942-947$.

7 Popovic V, Miljic D, Micic D, Damjanovic S, Arvat E, Ghigo E, Dieguez C \& Casanueva FF. Ghrelin main action on the regulation of growth hormone release is exerted at hypothalamic level. Journal of Clinical Endocrinology and Metabolism $2003 \mathbf{8 8}$ 3450-3453.

8 Smith RG, Van der Ploeg LH, Howard AD, Feighner SD, Cheng K, Hickey GJ, Wyvratt MJ Jr, Fisher MH, Nargund RP \& Patchett AA. Peptidomimetic regulation of growth hormone secretion. Endocrine Reviews 199718 621-645.

9 Tannenbaum GS, Epelbaum J \& Bowers CY. Interrelationship between the novel peptide ghrelin and somatostatin/growth hormone-releasing hormone in regulation of pulsatile growth hormone secretion. Endocrinology 2003144 967-974.

10 Borges MH, DiNinno FB \& Lengyel AM. Different effects of growth hormone releasing peptide (GHRP-6) and GH-releasing hormone on GH release in endogenous and exogenous hypercortisolism. Clinical Endocrinology 199746 713-718.

11 Leal-Cerro A, Torres E, Soto A, Dios E, Deghenghi R, Arvat E, Ghigo E, Dieguez C \& Casanueva FF. Ghrelin is no longer able to stimulate growth hormone secretion in patients with Cushing's syndrome but instead induces exaggerated corticotropin and cortisol responses. Neuroendocrinology 200276 390-396.

12 Correa-Silva SR, Nascif S \& Lengyel AM. Decreased GH secretion and enhanced ACTH and cortisol release after ghrelin administration in Cushing's disease: comparison with GH-releasing peptide-6 (GHRP-6) and GHRH. Pituitary 20069 101-107.

13 Leal-Cerro A, Pumar A, Villamil F, Astorga R, Dieguez C \& Casanueva FF. Growth hormone releasing hormone priming increases growth hormone secretion in patients with Cushing's syndrome. Clinical Endocrinology 199338 399-403.

14 Leal-Cerro A, Venegas E, Garcia-Pesquera F, Jimenez LM, Astorga R, Casanueva FF \& Dieguez C. Enhanced growth hormone $(\mathrm{GH})$ responsiveness to $\mathrm{GH}$-releasing hormone after dietary restriction in patients with Cushing's syndrome. Clinical Endocrinology $1998 \mathbf{4 8} 117-121$.

15 Leal-Cerro A, Jimenez LM, Astorga R, Fernandez-Lopez I, Dieguez C \& Casanueva FF. Acute pharmacological reduction of plasma free fatty acids enhances the growth hormone (GH)releasing hormone mediated GH secretion in patients with Cushing's syndrome. Journal of Clinical Endocrinology and Metabolism 199782 3165-3168.

16 Tyrrell JB, Wiener-Kronish J, Lorenzi M, Brooks RM \& Forsham PH. Cushing's disease: growth hormone response to hypoglycemia after correction of hypercortisolism. Journal of Clinical Endocrinology and Metabolism 197744 218-221.

17 Kuwayama A, Kageyama N, Nakane T, Watanabe M \& Kanie N. Anterior pituitary function after transsphenoidal selective adenomectomy in patients with Cushing's disease. Journal of Clinical Endocrinology and Metabolism 198153 165-173.

18 Burke CW, Adams CB, Esiri MM, Morris C \& Bevan JS. Transsphenoidal surgery for Cushing's disease: does what is removed determine the endocrine outcome? Clinical Endocrinology 199033 525-537.

19 Magiakou MA, Mastorakos G, Gomez MT, Rose SR \& Chrousos GP. Suppressed spontaneous and stimulated growth hormone secretion in patients with Cushing's disease before and after surgical cure. Journal of Clinical Endocrinology and Metabolism 1994 78 131-137.
20 Hughes NR, Lissett CA \& Shalet SM. Growth hormone status following treatment for Cushing's syndrome. Clinical Endocrinology 199951 61-66.

21 Tzanela M, Karavitaki N, Stylianidou C, Tsagarakis S \& Thalassinos NC. Assessment of GH reserve before and after successful treatment of adult patients with Cushing's syndrome. Clinical Endocrinology 200460 309-314.

22 Pecori Giraldi F, Andrioli M, De Marinis L, Bianchi A, Giampietro A, De Martin M, Sacco E, Scacchi M, Pontecorvi A \& Cavagnini F. Significant GH deficiency after long-term cure by surgery in adult patients with Cushing's disease. European Journal Endocrinology 2007156 233-239.

23 Engelhardt D \& Weber MM. Therapy of Cushing's syndrome with steroid biosynthesis inhibitors. Journal of Steroid Biochemistry and Molecular Biology 199449 261-267.

24 Sonino N, Boscaro M, Paoletta A, Mantero F \& Ziliotto D. Ketoconazole treatment in Cushing's syndrome: experience in 34 patients. Clinical Endocrinology 199135 347-352.

25 Vieira JG, Nakamura OH \& Carvalho VM. Measurement of free urinary cortisol and cortisone using liquid chromatography associated with tandem mass spectrometry method. Arquivos Brasileiros de Endocrinologia e Metabologia 200549 291-298.

26 Correa-Silva SR, Nascif S, Silva MR, Molica P \& Lengyel AM. Effect of one month ketoconazole treatment on $\mathrm{GH}$, cortisol and ACTH release after ghrelin, GHRP-6 and GHRH administration in patients with Cushing's disease. Arquivos Brasileiros de Endocrinologia e Metabologia 200751 1110-1117.

27 Micic D, Macut D, Popovic V, Kendereski A, Sumarac-Dumanovic M, Zoric S, Dieguez C \& Casanueva FF. Growth hormone (GH) response to GH-releasing peptide-6 and GH-releasing hormone in normal-weight and overweight patients with non-insulin-dependent diabetes mellitus. Metabolism 199948 525-530.

28 Alvarez-Castro P, Isidoro ML, Garcia-Buela J, Leal-Cerro A, Broglio T, Tassone F, Ghigo E, Dieguez C, Casanueva FF \& Cordido F. Marked GH secretion after ghrelin alone or combined with GH-releasing hormone (GHRH) in obese patients. Clinical Endocrinology $200461250-255$.

29 Borges JL, Blizzard RM, Evans WS, Furlanetto R, Rogol AD, Kaiser DL, Rivier J, Vale W \& Thorner MO. Stimulation of growth hormone $(\mathrm{GH})$ and somatomedin $\mathrm{C}$ in idiopathic GH-deficient subjects by intermittent pulsatile administration of synthetic human pancreatic tumor GH-releasing factor. Journal of Clinical Endocrinology and Metabolism 198459 1-6.

30 Tamura H, Kamegai J, Sugihara H, Kineman RD, Frohman LA \& Wakabayashi I. Glucocorticoids regulate pituitary growth hormone secretagogue receptor gene expression. Journal of Neuroendocrinology 200012 481-485.

31 Luque RM, Gahete MD, Valentine RJ \& Kineman RD. Examination of the direct effects of metabolic factors on somatotrope function in a non-human primate model, Papio anubis. Journal of Molecular Endocrinology 200637 25-38.

32 Petersenn S, Rasch AC, Penshorn M, Beil FU \& Schulte HM. Genomic structure and transcriptional regulation of the human growth hormone secretagogue receptor. Endocrinology 2001142 $2649-2659$.

33 Kineman RD \& Luque RM. Evidence that ghrelin is as potent as growth hormone (GH)-releasing hormone (GHRH) in releasing GH from primary pituitary cell cultures of a nonhuman primate (Papio anubis), acting through intracellular signaling pathways distinct from GHRH. Endocrinology 2007148 4440-4449.

34 Casanueva FF, Camiña JP, Carreira MC, Pazos Y, Varga JL \& Schally AV. Growth hormone-releasing hormone as an agonist of the ghrelin receptor GHS-R1a. PNAS 2008105 20452-20457.

Received 10 August 2009

Accepted 13 August 2009 